\title{
An efficient synthesis of biaryls via noncatalysed anionic coupling of an arylsodium with haloarenes
}

\author{
Jean-Michel Becht, Arnaud Gissot, Alain Wagner* and Charles Mioskowski* \\ Université Louis Pasteur de Strasbourg, UMR 7514 associée au CNRS, Laboratoire de Synthèse Bioorganique, \\ Faculté de Pharmacie, 74 Route du Rhin, 67401 Illkirch-Graffenstaden, France
}

Received 11 October 2004; revised 22 October 2004; accepted 22 October 2004

\begin{abstract}
Noncatalysed anionic coupling of an arylsodium with haloarenes readily gives access to valuable biaryl structures. Compared to aryllithiums, the reaction with arylsodiums is faster and can be performed at lower temperature. The coupling with substituted haloarenes proceeds often with a high degree of regioselectivity. Since only cheap and readily available substrates are involved, this coupling is particularly suited for the large scale synthesis of basic biaryl building blocks.
\end{abstract}

Biaryls have found many applications in the fields of biologically active molecules, ${ }^{1}$ molecular recognition, ${ }^{2}$ nonlinear optic and ligands for catalysts. ${ }^{3}$ They are generally synthesised in high yields and under mild reaction conditions through $\mathrm{Pd}-$ or Ni-catalysed cross coupling reactions. ${ }^{4}$ Yet, Pd-catalysed cross couplings require organoboronic or organostannane reagents which are often tedious to prepare. Pd- or Ni-catalysts are also expensive and therefore quite unsuitable for the large scale preparation of basic biaryl building blocks. In this regard, we recently reported a straightforward noncatalysed anionic coupling of aryllithiums with haloarenes starting from readily available materials. ${ }^{5} \mathrm{We}$ have shown that the reaction of aryllithiums with substituted haloarenes proceeds often either via a regioselective aromatic nucleophilic substitution or via a regioselective addition of the aryllithium to an aryne intermediate. ${ }^{5,6} \mathrm{We}$ also demonstrated that arylsodiums offer an interesting alternative to aryllithiums especially in the large scale preparation of functionalised aromatic compounds. ${ }^{7}$ Indeed, arylsodiums are obtained via an efficient one-pot ortho-metallation procedure of aromatic substrates with a sodiated organic base generated in situ from chlorooctane and stoichiometric amounts of metallic sodium. ${ }^{7}$ Herein, we describe the reactivity and selectivity of the anionic coupling between an arylsodium and haloarenes and show the advantages associated with the use of an arylsodium in place of an aryllithium.

\footnotetext{
$\overline{\text { Keywords: }}$ Biaryls; Metallation; Arylsodiums; Aromatic substitution; Arynes.

* Corresponding authors. Tel.: +33 3902442 95; fax: +33 3902443

06; e-mail: alwag@ aspirine.u-strasbg.fr
}

The reactivity of arylsodiums was studied using 2-sodio1,3-dimethoxybenzene $\mathbf{1}$ and chlorobenzene $(\mathrm{X}=\mathrm{Cl})$ as model substrates (Table 1). Inspired by our previous results, ${ }^{5 a}$ 1,3-dimethoxybenzene was in situ orthometallated with the tandem chlorooctane/micronised sodium in THF at $\mathrm{rt}$ for $3 \mathrm{~h} .{ }^{7,8}$ Using the same reaction conditions than for aryllithiums, ${ }^{5 a}$ chlorobenzene was added dropwise at $r$ and the reaction mixture was heated at $65^{\circ} \mathrm{C}$ for $60 \mathrm{~min}$. We observed the exclusive formation of the biphenyl $\mathbf{3}$ in $75 \%$ yield, resulting probably from the reduction of $\mathbf{2}$ by the metallic sodium present in situ (entry 1). This hypothesis is supported by the excellent electron scavenging properties of biaryls. ${ }^{9}$

Table 1. Optimisation of the reaction conditions
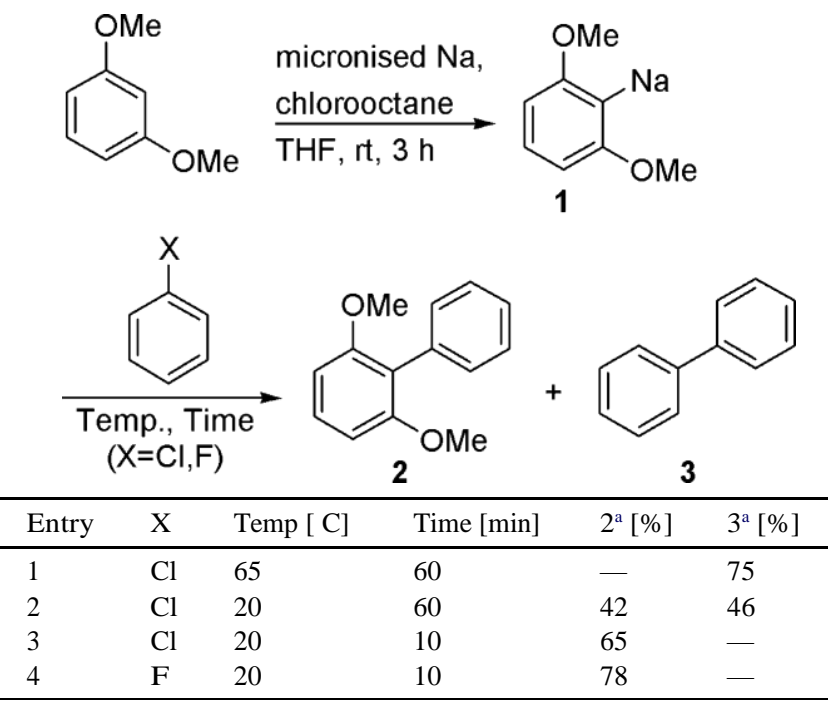

${ }^{a}$ Isolated overall yields after flash-chromatography on silica gel. Starting materials were recovered. 
Noteworthy, $\mathbf{3}$ was never observed with aryllithiums. ${ }^{5 a}$ Interestingly, we found that $\mathbf{2}$ and $\mathbf{3}$ were obtained in a 42:46 ratio when the coupling was carried out at $\mathrm{rt}$ for 60 min (entry 2). By lowering the reaction time to 10 min, 2 was obtained in an improved 65\% yield (entry $3)$. This result is in accordance with an early report of Ehrhart. ${ }^{10}$ In this case, no biphenyl was detected and the remaining starting material was recovered. Finally, an improved $78 \%$ yield was obtained by reacting 1 with fluorobenzene (entry 4$).^{6 f, 11}$

Next, we studied the regioselectivity in the anionic coupling of 1 with 2-, 3- and 4-chloroanisole (Table 2). Contrary to the report of Ehrhart, ${ }^{10}$ we found that 2- chloroanisole afforded the ortho-biaryl in $62 \%$ yield and $84 \%$ regioselectivity, through a chelation-driven aromatic nucleophilic substitution mechanism (entry 1). ${ }^{5 a} 3$-Chloroanisole gave the expected meta-biaryl with $94 \%$ regioselectivity and $58 \%$ yield, through a regioselective addition of $\mathbf{1}$ to an aryne intermediate (entry 3) ${ }^{5 a}$ Finally, 4-chloroanisole (entry 5 ) led to a 3:2 mixture of meta- and para-biaryls in $48 \%$ yield. Compared to 2-lithio-1,3-dimethoxybenzene, ${ }^{5 a} \mathbf{1}$ afforded the desired biaryls with comparable regioselectivities (entries 2, 4, 6).

Table 2. Reaction of 1 with 2-, 3- and 4-chloroanisole

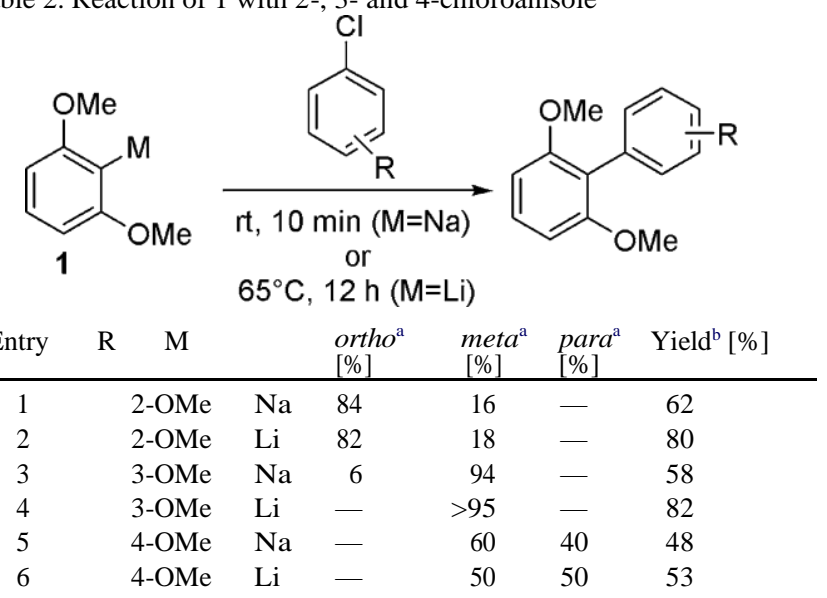

${ }^{a}$ Determined by GC analysis of the crude reaction mixture.

${ }^{\mathrm{b}}$ Isolated overall yields after flash-chromatography on silica gel. Starting materials were recovered.

In summary, we have reported a straightforward anionic coupling of an arylsodium with haloarenes. Compared to aryllithiums, the reaction with arylsodiums requires both shorter reaction time and lower temperature. The regioselectivities with substituted haloarenes are comparable to those obtained with aryllithiums. This anionic coupling was successfully carried out on a one mole scale without any noticeable loss in efficacy starting from readily available, stable and inexpensive starting materials. This method is therefore particularly suited for the large scale preparation of basic biaryls.

\section{Acknowledgements}

We thank the Ministère de 1 Education Nationale, de la Recherche et de la Technologie for financial support of this work through MENRT grants to J.-M.B. and A.G.

\section{References and notes}

1. (a) Chrysselis, M. C.; Rekka, E. A.; Kourounakis, P. N. J. Med. Chem. 2000, 43, 609-612; (b) Hallock, Y. F.; Cardellina, J. H., II; Schäffer, M.; Bringmann, G.; François, G.; Boyd, M. R. Bioorg. Med. Chem. Lett. 1998, 8, 17291734; (c) Milton, J.; Slater, M. J.; Bird, A. J.; Spinks, D.; Scott, G.; Price, C. E.; Downing, S.; Green,

D. V. S.; Madar, S.; Bethell, R.; Stammers, D. K. Bioorg. Med. Chem. Lett. 1998, 8, 2623-2628; (d) Bringmann, G.; Holenz, J.; Weirich, R.; Rü benacker, M.; Funke, C. Tetrahedron 1998, 54, 497-512.

2. Schulte, J. L.; Laschat, S.; Vill, V.; Nishikawa, E.; Finkelmann, H.; Nimtz, M. Eur. J. Org. Chem. 1998, 24992506.

3. Spivey, A. C.; Fekner, T.; Spey, S. E. J. Org. Chem. 2000, $65,3154-3159$.

4. (a) Hassan, J.; Sévignon, M.; Gozzi, C.; Schulz, E.; Lemaire, M. Chem. Rev. 2002, 102, 1359-1469; (b) MetalCatalyzed, Cross Coupling Reactions; Diederich, F., Stang, P. J., Eds.; Wiley-VCH: Weinheim, Germany, 1998; (c) Heck, R. F. Palladium reagents in organic synthesis; Academic: New York, 1985; (d) Tsuji, J. Palladium Reagents and Catalysis, Innovations in Organic Synthesis; Wiley: Chichester, UK, 1995.

5. (a) Becht, J.-M.; Gissot, A.; Wagner, A.; Mioskowski, C. Chem. Eur. J. 2003, 9, 3209-3215; (b) Becht, J.-M.; Ngouela, S.; Wagner, A.; Mioskowski, C. Tetrahedron 2004, 60, 6853-6857.

6. (a) Hoffmann, R. W. Chem. Rev. 1965, 98, 222-234; (b) Wittig, G.; Hoffmann, R. W. Chem. Ber. 1962, 2729-2734; (c) Benkeser, R. A.; Severson, R. G. J. Am. Chem. Soc. 1949, 71, 3838-3839; (d) Benkeser, R. A.; Buting, W. E. J. Am. Chem. Soc. 1952, 74, 3011-3014; (e) Adejare, A.; Miller, D. D. Tetrahedron Lett. 1984, 25, 5597-5598; (f) Friedman, L.; Chlebowski, J. F. J. Am. Chem. Soc. 1969, 91, 4864-4871.

7. Gissot, A.; Becht, J.-M.; Desmurs, J. R.; Pévère, V.; Wagner, A.; Mioskowski, C. Angew. Chem., Int. Ed. 2002, 41(2), 340-343.

8. All the reactions were performed using a $30 \%$ dispersion of micronised sodium in toluene from Aldrich, reference 47,226-3, cas number : [7440-23-5].

9. (a) Freeman, P. K.; Hutchinson, L. L. J. Org. Chem. 1980, 45, 1924-1930; (b) Freeman, P. K.; Hutchinson, L. L. Tetrahedron Lett. 1976, 17, 1849-1852.

10.Ehrhart, G. Chem. Ber. 1963, 96, 2042-2046.

11.Typical procedure for the synthesis of 2 . A solution of chlorooctane $(5.90 \mathrm{mmol}, 1.00 \mathrm{~mL}, 1.0$ equiv) in anhydrous THF $(8 \mathrm{~mL})$ was added dropwise at $\mathrm{rt}$ under an atmosphere of argon to a suspension of micronised sodium (30\% in toluene, $16.5 \mathrm{mmol}, 379 \mathrm{mg}, 2.8$ equiv) and 1,3dimethoxybenzene $(5.90 \mathrm{mmol}, 0.77 \mathrm{~mL}, 1.0$ equiv) in anhydrous THF ( $5 \mathrm{~mL})$. The reaction initiated within $5 \mathrm{~min}$ and was characterised by a slight increase in temperature. The remaining chlorooctane solution was then added dropwise at constant temperature. The reaction mixture was stirred for $3 \mathrm{~h}$ at rt. A solution of fluorobenzene $(2.65 \mathrm{mmol}$, $0.25 \mathrm{~mL}, 0.45$ equiv) in anhydrous THF $(2 \mathrm{~mL})$ was added dropwise at rt. After stirring for $10 \mathrm{~min}$ at $\mathrm{rt}$, the reaction mixture was quenched by addition of $\mathrm{H}_{2} \mathrm{O}(10 \mathrm{~mL})$. The aqueous layer was extracted twice with $\mathrm{Et}_{2} \mathrm{O}$ (total $30 \mathrm{~mL}$ ) and the combined organic layers were dried over $\mathrm{MgSO}_{4}$, filtered under vacuum and concentrated under reduced pressure. The residue was purified by flashchromatography on silica gel to afford 2 in $78 \%$ yield. 